Cite this: J. Mater. Chem. C, 2014, 2, 4692

Received 24th February 2014

Accepted 24th March 2014

DOI: $10.1039 / c 4 t c 00371 c$

www.rsc.org/MaterialsC

\section{Photochromic and photomechanical responses of an amorphous diarylethene-based polymer: a spectroscopic ellipsometry investigation of ultrathin films $\dagger$}

\author{
Chiara Toccafondi,,$^{\mathrm{a}}$ Luca Occhi, ${ }^{\mathrm{b}}$ Ornella Cavalleri, ${ }^{\mathrm{a}}$ Amanda Penco, ${ }^{a}$ \\ Rossella Castagna, ${ }^{c}$ Andrea Bianco, ${ }^{d}$ Chiara Bertarelli, ${ }^{c e}$ Davide Comoretto ${ }^{b}$ \\ and Maurizio Canepa*a
}

\begin{abstract}
This work deals with very thin (14-40 nm) films of a polyester containing diarylethene units in the main chain spin cast on a silicon wafer. By irradiation with UV light the colourless form turns blue due to the appearance of a strong absorption band centred at about $600 \mathrm{~nm}$. The coloured state is thermally stable and the backward conversion can be triggered with visible light. Comparison of broadband (245-1700 nm) spectroscopic ellipsometry data with simulations based on an isotropic, Kramers-Kronig consistent, multiple-resonance model allowed us to determine the complex index of refraction $\tilde{n}$ of the film in its blue and colourless forms. The refractive index of the blue phase neatly exceeds that of the transparent form for wavelengths in the NIR. In particular, out of resonance, at $\lambda \sim 1700 \mathrm{~nm}, \Delta \operatorname{Re}(\tilde{n}) \sim 0.05$. Parallel to the $\Delta \operatorname{Re}(\tilde{n})$ increase, the analysis of ellipsometry data suggests a decrease of the film thickness (about $1.5 \%)$ during the transition from the open (transparent) to the closed (coloured) form.
\end{abstract}

\section{Introduction}

Photonic polymers are gaining increasing interest for applications where standard inorganic materials are less competitive in terms of the mechanical flexibility of devices, processing costs or properties such as color tunability and large active area. ${ }^{\mathbf{1}}$ In this field, photochromic materials, such as azobenzenes and diarylethenes, whose colour and other physico-chemical properties can be modulated by light stimulation, find growing applications in memory devices, switches, actuators, tunable filters, volume phase holographic gratings, optical nanopatterning and multiplexing/demultiplexing devices. ${ }^{2-11}$ Applications aiming to exploit

${ }^{a}$ Dipartimento di Fisica, Università di Genova and CNISM, via Dodecaneso 33, Genova, Italy.E-mail: canepa@fisica.unige.it

${ }^{b}$ Dipartimento di Chimica e Chimica Industriale, Università di Genova, via Dodecaneso 31, Genova, Italy

'Dipartimento di Chimica, Materiali ed Ingegneria Chimica "G. Natta", Politecnico di Milano, Piazza Leonardo da Vinci 32, 20133 Milano, Italy

${ }^{d}$ INAF - Osservatorio Astronomico di Brera, via Bianchi 46, 23807 Merate, Italy

${ }^{e}$ Center for Nano Science and Technology @PoliMi, Istituto Italiano di Tecnologia, via Pascoli 70/3, 20133 Milano, Italy

$\dagger$ Electronic supplementary information (ESI) available: Definition of the MSE function; UV-vis absorption spectra of p-DTE in chloroform solution; AFM images of films; the extinction coefficient of the polymer film as a function of energy; details about the comparison between experimental and simulated spectra of representative samples with different thicknesses. See DOI: 10.1039/c4tc00371c

† Present address: Istituto Italiano di Tecnologia, via Morego 30, Genova. very thin films require sensitive and non-destructive characterization techniques. Optical methods, traditionally used for the determination of optical properties of thin films, ${ }^{12-14}$ have been used to investigate crystallization or non-equilibrium morphologies thus integrating electron microscopy or X-ray diffraction studies. ${ }^{15,16}$ UV-vis Spectroscopic Ellipsometry (SE) may couple thickness sensitivity, down to the monolayer limit, ${ }^{17-20}$ to real-time information on broad-band spectroscopic dielectric properties, which can be possibly correlated with morphological issues. ${ }^{21}$

Indeed, polymers (and polymerization) have attracted SE studies since the early development of the technique; ${ }^{22-24}$ more recently, SE has found growing application to very thin films in the fields e.g. of organic electronics, ${ }^{13,25}$ smart surfaces ${ }^{21,26}$ and other stimuli responsive polymers. ${ }^{20,27,28} \mathrm{SE}$ becomes particularly appealing in the investigation of ultra thin films whose optical and morphological properties may significantly differ from the bulk form ones. This is the case e.g. of conjugated polymers, where the combination of optical and morphological changes provides information on processes affecting the performances of optoelectronic devices such as the evolution of structure, relaxation of non-equilibrium morphology, crystallization, phase separation and solvent evaporation. ${ }^{28-33}$ From this perspective, it is promising to exploit real-time $\mathrm{SE}$ in the investigation of the light-triggered conversion of films of photochromic polymers towards the ultra thin thickness limit.

Diarylethenes are well-known photochromic compounds endowed with thermal stability and high fatigue resistance., 

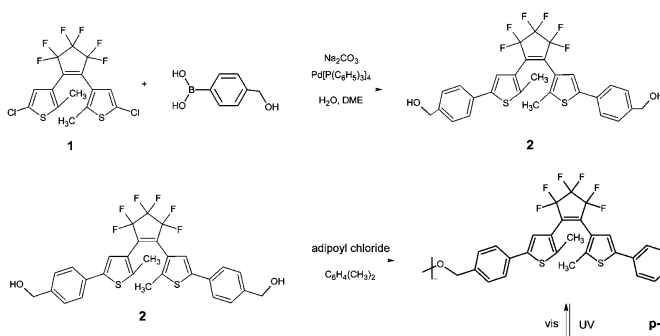

|

Blended (a few percent by weight) into transparent polymer matrices, their refractive indices may appreciably change across the transition. ${ }^{2,5,34}$

In order to overcome possible aggregation phenomena, which enhance light scattering and hamper the optical quality of molecular films, the insertion of the diarylethene moiety into a polymer chain can be of great advantage. Main- ${ }^{4,8,35,36}$ and sidechain $^{37,38}$ diarylethene-based photochromic polymers combine a large content of active units in the bulk, which leads to a high optical density, and processing features which provide films of good optical quality. The material under investigation here is a polyester containing diarylethene units in the main chain ( $\mathrm{p}$ DTE, Fig. 1). The tetramethylene spacer imparts good flexibility to the molecular backbone, thus improving the solubility in common organic solvents and, in turn, material processing. By irradiation with UV light the transparent, open form turns closed and coloured as schematically indicated in Fig. 1 . The backward conversion of the thermally stable, coloured state is obtained by exposure to red light.

The main goal of this work was the determination of the broad-band $(245-1700 \mathrm{~nm})$ dielectric function of the photochromic polymer in each of the two forms. Significant transition-induced changes of the complex refractive index, strategic for photonic applications, were expected from results in the literature, ${ }^{2,4,8,34,39,40}$ possibly strong for high density films. ${ }^{41} \mathrm{~A}$ second intriguing objective was to exploit SE to gain insight into changes of thickness of photochromic ultrathin films interesting for the development of photo-responsive actuators. ${ }^{42,43}$ We considered films with thickness on the order of a very few tens of $\mathrm{nm}$, one order of magnitude thinner than systems hitherto investigated, ${ }^{5,39,41}$ at the limit of the realm of so-called ultrathin films.

\section{Materials and methods}

\subsection{Materials and film preparation}

Photochromic material. The diarylethene-based polyester was synthesized by step-polymerization between the 1,2-bis-(2-methyl- 5-(p-hydroxymethylphenyl)-3-thienyl)perfluorocyclopentene and adipoyl chloride. This diarylethene monomer was preferred to the 1,2-bis-(2-methyl-5-(hydroxyphenyl)-3-thienyl)perfluorocyclopentene, which is difficult to purify by flash chromatography of the raw product and is rather unstable.

Reactions have been carried out under a dry, oxygen-free argon atmosphere. Unless otherwise specified, all reagents and catalysts were of commercial grade (Aldrich, Alfa Aesar). ${ }^{1} \mathrm{H}$ NMR spectra of a solution in $\mathrm{CDCl}_{3}$ were recorded on a Bruker AXR 400 spectrometer at $400 \mathrm{MHz}$.

1,2-Bis-(5-p-hydroxylmethylphenyl-2-methyl-3-thienyl)perfluorocyclopentene (2). Following the reaction procedure described in ref. 44, 4-(hydroxymethyl)phenyl boronic acid (0.383 g, $2.52 \mathrm{mmol}$ ), 1,2-bis-(2-methyl-5-chloro-3-thienyl)perfluorocyclopentene (1) (0.5 g, $1.14 \mathrm{mmol}), \mathrm{Na}_{2} \mathrm{CO}_{3} \cdot 10 \mathrm{H}_{2} \mathrm{O}(1.31$ $\mathrm{g}, 4.58 \mathrm{mmol})$ and $\mathrm{Pd}\left(\mathrm{PPh}_{3}\right)_{4}(0.132 \mathrm{~g}, 0.11 \mathrm{mmol})$ were dissolved in previously degassed DME $(20 \mathrm{~mL})$ and water $(5 \mathrm{~mL})$. The reaction mixture was refluxed under argon for 24 hours, then extracted with diethyl ether and water and the combined organic layers were dried over $\mathrm{Na}_{2} \mathrm{SO}_{4}$. Purification by flash chromatography on silica gel (ethyl acetate) provided $570 \mathrm{mg}$ of the desired product in $86 \%$ yield.

$\left({ }^{1} \mathrm{H}\right.$ NMR $\left(400 \mathrm{MHz}, \mathrm{CDCl}_{3}\right): \delta 7.54(\mathrm{~d}, 4 \mathrm{H}, J(\mathrm{H}, \mathrm{H})=8.2 \mathrm{~Hz})$, $7.38(\mathrm{~d}, 4 \mathrm{H}, J(\mathrm{H}, \mathrm{H})=8.2 \mathrm{~Hz}), 7.28(\mathrm{~s}, 2 \mathrm{H}), 4.71(\mathrm{~s}, 4 \mathrm{H}), 1.97(\mathrm{~s}$, 6H) ppm.)

p-DTE. 1,2-Bis-(2-methyl-4-(p-hydroxylmethylphenyl)-3-thienyl)perfluorocyclopentene (2) (0.5 g, $0.86 \mathrm{mmol})$ and adipoyl chloride $(0.125 \mathrm{~mL}$, in stoichiometric ratio $1: 1)$ in anhydrous xylene $(30 \mathrm{~mL})$ were stirred at reflux for 120 hours. The reaction mixture was poured into petroleum ether under vigorous stirring, the white precipitate was filtered ( $330 \mathrm{mg}, 56 \%$ yield) and subsequently extracted with hot diethyl ether and chloroform, obtaining $140 \mathrm{mg}$ (24\% yield) and $190 \mathrm{mg}$ (32\% yield), respectively. No insoluble residue was recovered.

$\left({ }^{1} \mathrm{H}\right.$ NMR $\left(400 \mathrm{MHz}, \mathrm{CDCl}_{3}\right): \delta 7.51(\mathrm{~d}, 4 \mathrm{H}, J(\mathrm{H}, \mathrm{H})=8.09 \mathrm{~Hz})$, $7.37(\mathrm{~d}, 4 \mathrm{H}, J(\mathrm{H}, \mathrm{H})=8.09 \mathrm{~Hz}), 5.11(\mathrm{~s}, 4 \mathrm{H}), 2.38(\mathrm{t}, 4 \mathrm{H}), 1.98$ (s, 6H), $1.70(\mathrm{t}, 4 \mathrm{H}) \mathrm{ppm}$.)

Film preparation and processing. The wafers were carefully prepared and characterised by $\mathrm{SE}$, following procedures described in a previous study. ${ }^{45}$ Films were cast by spin coating (angular speed between 1800 and $3600 \mathrm{rpm}$ ) on $\mathrm{SiO}_{2} / \mathrm{Si}$ substrates using solutions with different concentrations $(5 \mathrm{mg}$ $\mathrm{mL}^{-1}$ and $15 \mathrm{mg} \mathrm{mL}^{-1}$ in toluene), obtaining thickness in the $14-40 \mathrm{~nm}$ range. After the deposition, the polymer was isomerized into its non-cyclic form using a red laser (MRL-III, 655 $\mathrm{nm}, 400 \mathrm{~mW}$, CNI Optoelectronics Tech. Co.). The cyclization reaction was obtained using a UV lamp (311 nm, PL-S 9W/01/2P 1CT, Philips).

\subsection{Methods}

Spectroscopic ellipsometry. Principles and applications of SE are described at length in books ${ }^{46-48}$ and recent reviews. ${ }^{49-51}$ Specific issues pertinent to ultrathin films and monolayers are also addressed in ref. 52. Standard ellipsometry investigates the coefficient $\rho=\tilde{r}_{\mathrm{p}} / \tilde{r}_{\mathrm{s}}=\tan \Psi \exp (i \Delta)$ where $\tilde{r}_{\mathrm{p}}$ and $\tilde{r}_{\mathrm{s}}$ are the complex Fresnel reflection coefficients for $\mathrm{p}$ - and s-polarization, 
respectively. Information on the optical (e.g. the complex index of refraction) and morphological properties (such as e.g. thickness, roughness) of the system under investigation is obtained from the comparison of data with simulations. To this aim, the system is usually modelled as a film (or a stack of layers) on a substrate. The thickness and/or some convenient quantity associated with the film optical properties are used as adjustable parameters in automated regression analysis of data looking for the best agreement between experimental $\Psi$ and $\Delta$ spectra and simulations, exploiting the minimization of a convenient biased estimator (in this case the Mean Squared Error, MSE, function $\left.{ }^{53,54}\right) \cdot \dagger$

Data reported in this paper, in the $245-1700 \mathrm{~nm}$ wavelength range, were obtained using a rotating compensator instrument (M-2000, J.A. Woollam Co. Inc.) equipped with a $75 \mathrm{~W}$ Xe lamp. The data analysis has been carried out using the software VASE supplied by the ellipsometer manufacturer. Measurements have been performed in a darkened room at $60^{\circ}, 65^{\circ} 70^{\circ}$ angles of incidence. The spot size on the sample was on the order of a few $\mathrm{mm}^{2}$. We performed static measurements, under steady-state conditions (transparent or coloured form of the polymer), and dynamic measurements, monitoring the photo-conversion process. Static measurements on the transparent form as well as dynamic measurements during the transition to the blue form were performed employing a glass sheet filtering out UV radiation from the beam $(\lambda<305 \mathrm{~nm})$. Static measurements on the blue form have been taken over the full spectral range. Transition-induced spectral changes were emphasized by calculating difference spectra between data collected on the coloured and transparent phase $\left(\delta \Delta=\Delta_{\text {blue }}-\Delta_{\text {transp }}, \delta \Psi=\Psi_{\text {blue }}-\Psi_{\text {transp }}\right)$, adapting approaches we recently applied to study molecular monolayers on solid substrates. ${ }^{55-59}$ SE data were complemented with AFM analysis of the film surface morphology $\cdot \dot{\dagger}$

\section{Results and discussion}

Representative static $\Psi$ and $\Delta$ spectra obtained on very thin films of p-DTE, in the colourless and blue form, are presented in Fig. 2-A (on the example of $\mathrm{a} \approx 35 \mathrm{~nm}$ thick film). The spectral differences between the two isomers are emphasized in Fig. 2-B. The $\delta \Psi$ pattern shows two evident negative structures, the sharpest at about $330 \mathrm{~nm}$, and a broad one peaked at about 600 $\mathrm{nm}$, whose position agrees with optical absorptions of the molecule measured in solution. $\dagger \delta \Psi$ values vanish for $\lambda$ in the NIR region. Regarding $\delta \Delta$ data, one can note the relatively broad, wiggling features in the $400-800 \mathrm{~nm}$ range, in good correspondence with the negative features in $\delta \Psi$ data. The $\delta \Delta$ values remain negative in the NIR range. The situation resembles the one encountered in the study of chromophores on transparent substrates, ${ }^{60}$ where $\delta \Psi$ and $\delta \Delta$ spectra were affected by adsorption-induced variation of the imaginary and real part of $\tilde{n}$, respectively. Such a relationship between the spectral features in Fig. 2-B and the optical properties of the blue form, intimately connected to Kramers-Kronig relationships, will be more evident after the comparison with simulations.

Fig. 3-A, reporting the evolution of the SE data during the irradiation at constant UV photon flux of an initially transparent

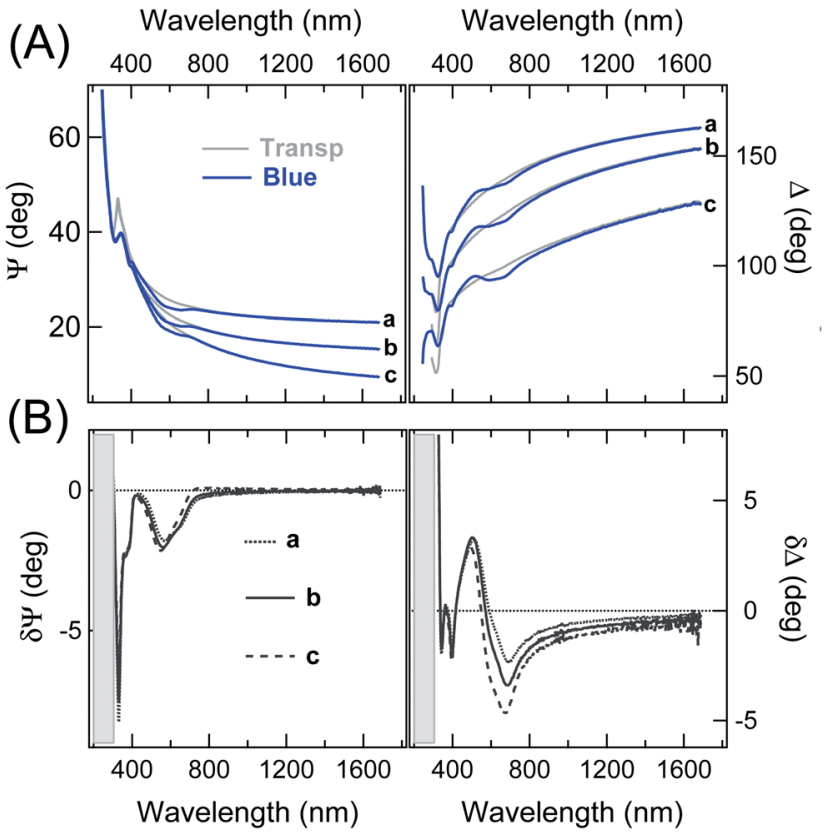

Fig. 2 (A) SE spectra of very thin films of p-DTE (thickness $\sim 35 \mathrm{~nm}$ ) in the colourless and blue form. Data are reported for three angles of incidence $\left((\mathrm{a}) 60^{\circ}\right.$, (b) $65^{\circ}$ and $\left.(\mathrm{c}) 70^{\circ}\right)$ (B) difference spectra $(\delta \Psi(\Delta)=$ $\left.\Psi(\Delta)_{\text {blue }}-\Psi(\Delta)_{\text {transp }}\right)$ obtained from data of panel A.

film, nicely illustrates the capability of SE to monitor relatively slow transients. For a better appreciation of the transition behaviour it may be useful to consider the value of a convenient ellipsometry parameter as a function of time, as it is often done in single wavelength ellipsometry studies. ${ }^{61}$ This is shown in panel (B) on the example of the $\delta \Psi$ value at $601 \mathrm{~nm}$. Even though $\delta \Psi$ data alone cannot be directly converted into extinction coefficient data, it is worth noting that the observed

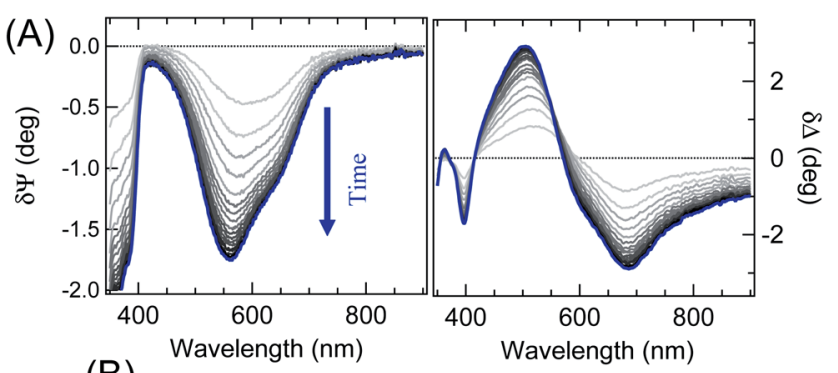

(B)

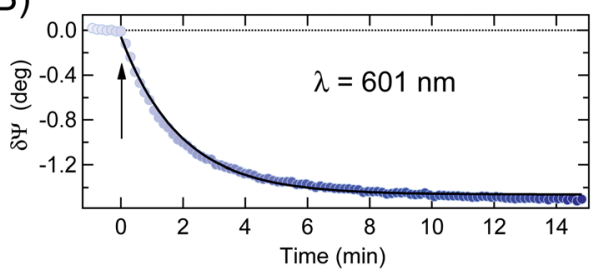

Fig. 3 (A) Selection of dynamic difference spectra $\left(65^{\circ}\right.$ angle of incidence) recorded during UV irradiation of the film in Fig. 2; the time separation among spectra is equal to 28 seconds. (B) Symbols: dynamic $\delta \Psi$ plot at $\lambda=600 \mathrm{~nm}$ during the photochromic transition ( $65^{\circ}$ angle of incidence). The arrow marks the onset of UV irradiation. The line shows an exponential fit to data. 
exponential behaviour is compatible with the conversion kinetics of relatively unorganized samples. ${ }^{62,63}$

Note that a close look at data in Fig. 3-B, before switching on the UV irradiation, is useful to appreciate the overall negligible effect of the probing beam on film coloration.

Coming to the quantitative analysis of SE data, the optical properties and the thickness of the photochromic film were determined by comparison with simulations of the optical system based on suitable models.

In principle, solvent cast films exhibit preferential orientation of the polymer backbones parallel to the substrate..$^{64,65}$ However, approaching the ultrathin thickness limit, correlations among optical fitting parameters and between optical parameters and thickness prevent intrinsically an unambiguous determination of the optical anisotropy by ellipsometry methods. ${ }^{66-68}$ Therefore, the simplest, isotropic two-layer model was considered, consisting of a homogeneous film on the substrate, in an air environment.

As amply documented in ref. 69, the optical constants deduced by the analysis of SE data through an isotropic model approximately correspond to the in-plane optical constants, while no information can be inferred about the extraordinary index.

We tested the introduction of the so-called surface roughness $(S R)$ layer. ${ }^{46-48}$ The $S R$ layer thickness, treated as a free parameter, was suppressed by the MSE minimization routine $(\dagger)$. In this regard, note that AFM measurements ( $\dagger$ ) indicated average roughness values ranging from $0.2 \mathrm{~nm}$, over very uniform regions (typically extending for some microns squared), up to $0.5 \div 0.7 \mathrm{~nm}$ over larger regions $(50 \times 50 \mu \mathrm{m})$ including some defective areas. We did not observe any significant change of the AFM roughness related to photo-conversion processes. Note however that the AFM laser operation may perturb the coloration of films.

The pseudo-dielectric functions of the substrate were predetermined from measurements carried out before film deposition. The film optical properties were described through a simple, multi-oscillator model preserving the $\mathrm{K}-\mathrm{K}$ consistency of data: $:^{24,33,58}$

$$
\varepsilon(h \nu)=\varepsilon_{\infty}+\sum_{i} G_{i}\left(A_{i}, E_{i}, \beta_{i}\right) .
$$

$\varepsilon_{\infty}$ is a real offset accounting for resonances located out of the measurement region. $A_{i}, E_{i}$ and $\beta_{i}$ are the amplitude, energy position, and broadening parameter, respectively, of the $i$-th oscillator, of Gaussian shape. $\varepsilon_{\infty}, A_{i}, E_{i}$ and $\beta_{i}$, as well as the film thickness, were considered as free parameters to be adjusted in the best-fit routine. Two sets of oscillators were necessary to reproduce the SE spectra of the two isomers. We opted for the criterion of keeping the number of oscillators in each set at minimum. A reliable guess of the oscillator parameters, useful to feed the fitting routine, was derived from transmission measurements in solution $(\dagger)$ or on thick films cast on fused silica. Regarding the visible range we assumed peaks of the same width. The comparison between experimental data and best-fit simulations (multi-angle analysis) for a representative sample is presented in Fig. 4. The K-K consistent real $\operatorname{Re}(\tilde{n})$ and imaginary $\operatorname{Im}(\tilde{n})$ part of the complex refractive index of the blue and transparent phase derived from the best fit in Fig. 4 are shown in Fig. 5. The curves are fully representative of very similar results obtained for several $22-38 \mathrm{~nm}$ thick films ( $\dagger$ ). Note that plotting $\operatorname{Im}(\tilde{n})$ as a function of photon energy is a choice more useful to emphasize the contribution of each oscillator assumed in the fit $(\dagger)$. The attainment of the best fit of the blue-phase spectra required a minimum of two oscillators in the visible range, located at about $620 \mathrm{~nm}(\sim 2.0 \mathrm{eV})$ and $540 \mathrm{~nm}$ $(\sim 2.3 \mathrm{eV})$, and four in the UV. The nearest UV absorption (about $385 \mathrm{~nm}, 3.2 \mathrm{eV}$ ) is quenched in the transparent form, in agreement with the literature on related systems. ${ }^{39,41}$ An even better reproduction of the data in the $400-800 \mathrm{~nm}$ range could be obtained considering (i) three narrower peaks instead of two or (ii) independent broadening parameters for the two peaks. However, in both cases the number of free parameters increased and the improvement of MSE was overall poor.

Regarding the transparent phase, except for some blue phase residuals, one broad and intense oscillator in the UV, centred at $306 \mathrm{~nm}$, was enough to fit the data. Coming back to Fig. 4 and zooming in the visible range, one can observe that the experimental features related to blue-phase residuals in panel B are in practice discernible only at $70^{\circ}$ of incidence; indeed, a reasonably good fit of the data can be obtained also for a perfectly uncoloured film. Thus, the small peak of $\operatorname{Im}(\tilde{n})$ in Fig. 5 at about $600 \mathrm{~nm}$ can be considered as an upper estimate for blue phase residuals and, in a sense, may represent a figure of the overall uncertainty in the characterization of the transparent state. Finally, a low amount of residuals, possibly due to incomplete photoisomerization and imperfect UV shielding, does not

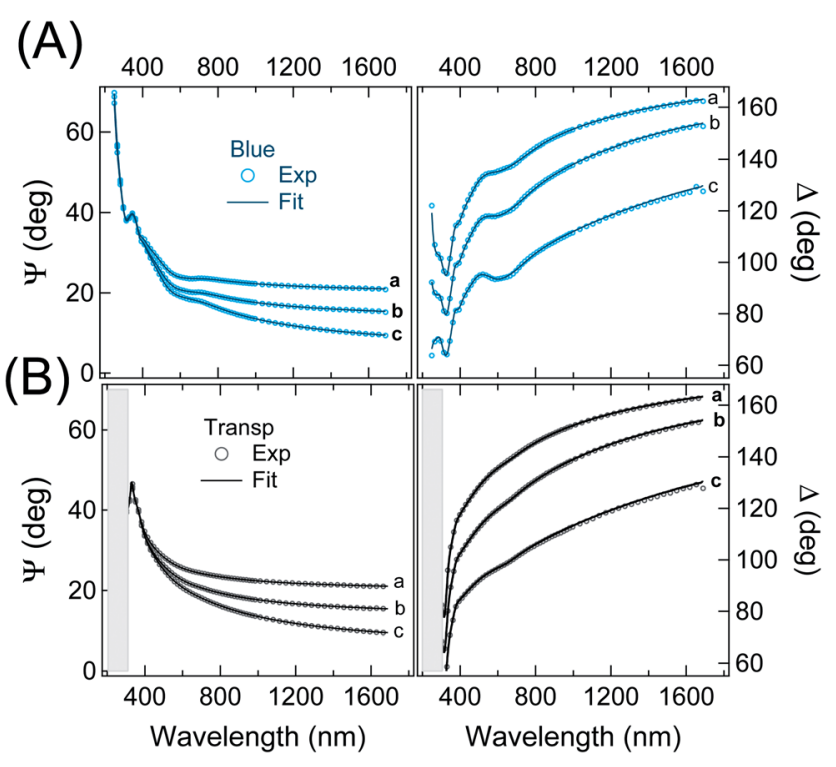

Fig. 4 Comparison between experimental and simulated (best-fit) SE spectra of a representative thin film of $p$-DTE in the (A) blue and (B) transparent phases (the same data as in Fig. 2). The resulting film thickness was $35.4 \pm 0.1 \mathrm{~nm}$ and $35.9 \pm 0.1$ for the blue and colourless phase, respectively. The resulting refractive index and extinction coefficient in the two phases are shown in Fig. 5. 


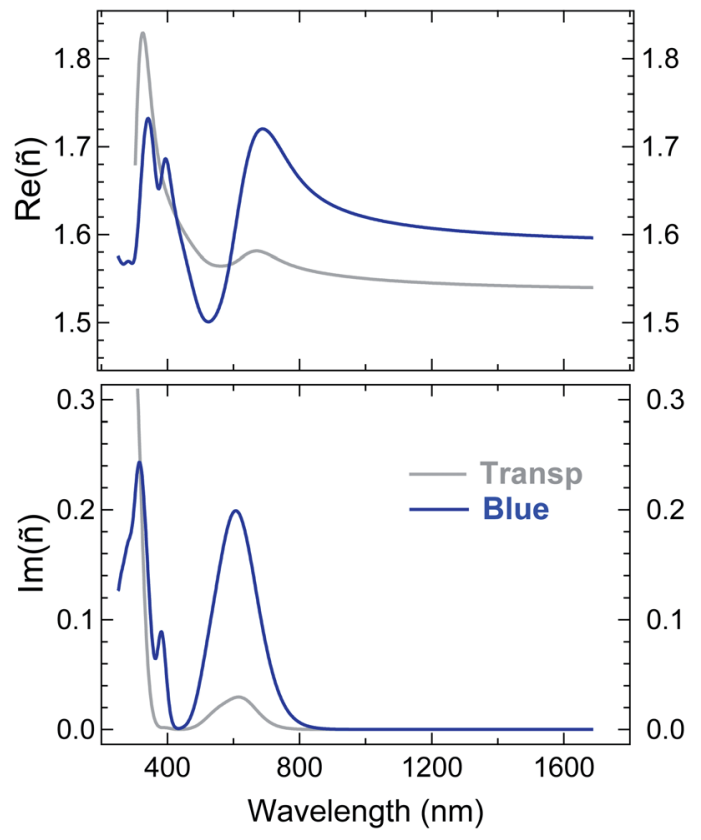

Fig. 5 Real and imaginary part of the complex refractive index of a representative film in the blue and transparent phase. The blue-form residuals in the transparent phase are due to incomplete photoisomerization.

invalidate the main conclusions of the analysis. In Fig. 5 note also the position of the isosbestic point, located by the fit at 315 $\mathrm{nm}$, in excellent agreement with measurements in solution $(\dagger)$. Another interesting feature in Fig. 5 is the neat difference of $\operatorname{Re}(\tilde{n})$ for the two phases for wavelength in the NIR region. Regarding this aspect, an extended review of previous studies can be found in ref. 8 . While a close comparison with the literature is not straightforward due to the diversity of materials, chromophore content and wavelengths considered in other studies. ${ }^{\mathbf{4 1 , 7 0}}$ we note that the resulting variation of the refractive index $\Delta \operatorname{Re}(\tilde{n})$ appears higher than some values reported for other diarylethenic polymers, e.g. $10^{-3}$ at $633 \mathrm{~nm}^{2}$ and $9 \times 10^{-3}$ at $830 \mathrm{~nm},,^{71}$ whereas it is definitely comparable with values of about 0.04 measured, with single wavelength methods (at about $800 \mathrm{~nm}$ ), for bulk phases of other diarylethene derivatives. ${ }^{39,40}$ Note that the choice of the wavelength, crucial for a reliable assessment of $\Delta \operatorname{Re}(\tilde{n})$, appears in some papers very close to the coloured polymer resonances. Another aspect to be discussed is the way the thickness parameter is considered in the data fitting. In our analysis it was allowed to vary upon the transition. The film thickness obtained e.g. for the represented sample in Fig. 5 showed a slight contraction, from 35.9 to $35.4 \mathrm{~nm}$, from the open form to the closed form. Such a trend was observed for all films considered in our experiment $(\dagger)$ and, to the best of our knowledge, is the first indication of a photomechanical response of diarylethene amorphous films. The thickness variation is tentatively assigned to film density changes induced by the ring-closure. Variations of density have been observed for several diarylethenes in crystalline form, the ring closure being accompanied by either an increase $\mathrm{e}^{72-77}$ or a decrease of density ${ }^{77-79}$ depending on the specific molecular structure. In the former cases, changes of density of $0.39-5.6 \%$ have been reported whereas a more limited variation ranging from 0.14 to $1.6 \%$ is shown when a density decrease results from the ring closure. If we preferably refer to the structures that are similar to the monomeric unit of p-DTE, a variation of $1.38 \%$ is reported in the case of 1,2-bis(2-methyl-5-phenyl-3thienyl)perfluorocyclopentene $\mathrm{e}^{72}$ and $2.62 \%$ for one polymorph of the 1,2-bis(2-methyl-5-( $p$-methoxyphenyl)-3-thienyl)perfluorocyclopentene. ${ }^{77}$

In a previous $\mathrm{SE}$ investigation of a dithienylethene embedded in the PMMA matrix ${ }^{5}$ the thickness parameter $(660$ $\mathrm{nm}$ ) was assumed constant across the photochromic transition and $\Delta \operatorname{Re}(\tilde{n})$ was estimated to be $5 \times 10^{-3}$. Following ref. 5 we made a check on the correlation between thickness and the refractive index, looking at the best fit on the transparent phase while keeping the thickness at the value found on the blue form; at the expense of a reduction of the fit quality (MSE $=13$ instead of 7), we found an increased value of $\operatorname{Re}(\tilde{n})$ (1.57 instead of 1.54 at $1700 \mathrm{~nm}$ ), still significantly lower than the corresponding value in the blue phase (about 1.60).

The discussion so far focused on $30-40 \mathrm{~nm}$ thick films, for which the relatively sharp ellipsometric contrast between the uncoloured and blue form (Fig. 2-B) guaranteed a robust analysis of data. We were able to obtain a satisfactory reproduction of SE experimental data for film thickness down to the $20 \mathrm{~nm}$ limit, with relatively small adjustments of the optical parameters in Fig. 5. Regarding even thinner films (14-17 nm), the spectral differences between the two isomers become smaller and smaller $(\dagger)$ and we opted to analyse the data keeping the optical absorption parameters of the blue form at the same values obtained in the analysis of the thicker films, in practice fitting only the film thickness. Within this approximation, we observe that the analysis of ultrathin films upon film colouration confirmed both a positive variation of $\operatorname{Re}(\tilde{n})$ and a small decrease of thickness. $\dagger$

\section{Concluding remarks}

This work focused on the characterization of the optical properties of very thin films of a photochromic polymer spin cast on a silicon wafer, carried out by application of broad-band spectroscopic ellipsometry. The use of a rotating compensator ellipsometer allowed us to perform a real time characterization of the photochromic transition during UV irradiation of the sample, clearly identifying ellipsometric features related to the polymer colour. Through the comparison of SE data with simulations based on an isotropic multi-resonance model accounting for molecular UV-vis absorptions, we determined the complex index of refraction of the compound in both the blue and colourless forms in a spectral region extending from the UV to the NIR range (245-1700 $\mathrm{nm}$ ). Results obtained for films in the 14-40 $\mathrm{nm}$ thickness range indicate that the real part of the refractive index of the blue phase neatly exceeds that of the transparent form for wavelengths above $600 \mathrm{~nm}: \Delta \operatorname{Re}(\tilde{n})$ is $\sim 0.05$ in the IR limit. Interestingly, the analysis of data, within the approximations involved in the proposed model, indicates a decrease (about 1.5\%) of thickness during the transition from 
the open (transparent) to the closed (blue) form, assigned to film density changes induced by the ring-closure process. The results of this work pave the way for the exploitation of ultrathin photochromic films in stimuli responsive photonic crystal structures and related devices, as well as in photo-responsive actuators.

\section{Acknowledgements}

This work received partial support from the University of Genova (PRA grant 2011-12). Partial support from the UE FP7 Opticon Project is also acknowledged.

\section{References}

1 J. Clark and G. Lanzani, Nat. Photonics, 2010, 4, 438-446.

2 N. Tanio and M. Irie, Jpn. J. Appl. Phys., 1994, 33, 39423946.

3 M. Irie, Chem. Rev., 2000, 100, 1685-1716.

$4 \mathrm{H}$. Cho and E. Kim, Macromolecules, 2002, 35, 8684-8687.

5 C. Bertarelli, A. Bianco, F. D'Amore, M. Gallazzi and G. Zerbi, Adv. Funct. Mater., 2004, 14, 357-363.

6 L. Angiolini, T. Benelli, L. Giorgini and E. Salatelli, Macromolecules, 2006, 39, 3731-3737.

7 T. Ikeda, J.-i. Mamiya and Y. Yu, Angew. Chem., Int. Ed., 2007, 46, 506-528.

8 C. Bertarelli, A. Bianco, R. Castagna and G. Pariani, J. Photochem. Photobiol., C, 2011, 12, 106-125.

9 S. Menghetti, M. Alderighi, G. Galli, F. Tantussi, M. Morandini, F. Fuso and M. Allegrini, J. Mate. Chem., 2012, 22, 14510-14517.

10 J. Garca-Amors and D. Velasco, Beilstein J. Org. Chem., 2012, 8, 1003-1017.

11 A. Ryabchun, A. Bobrovsky, A. Sobolewska, V. Shibaev and J. Stumpe, J. Mater. Chem., 2012, 22, 6245-6250.

12 D. Comoretto, G. Dellepiane, F. Marabelli, J. Cornil, D. A. dos Santos, J. L. Brédas and D. Moses, Phys. Rev. B: Condens. Matter Mater. Phys., 2000, 62, 10173-10184.

13 M. Campoy-Quiles, G. Heliotis, R. Xia, M. Ariu, M. Pintani, P. Etchegoin and D. Bradley, Adv. Funct. Mater., 2005, 15, 925-933.

14 C. Soci, D. Comoretto, F. Marabelli and D. Moses, Phys. Rev. B: Condens. Matter Mater. Phys., 2007, 75, 075204.

15 M. Brinkmann, F. Chandezon, R. B. Pansu and C. JulienRabant, Adv. Funct. Mater., 2009, 19, 2759-2766.

16 N. Sary, F. Richard, C. Brochon, N. Leclerc, P. Lvque, J.-N. Audinot, S. Berson, T. Heiser, G. Hadziioannou and R. Mezzenga, Adv. Mater., 2010, 22, 763-768.

17 K. A. Bell, L. Mantese, U. Rossow and D. E. Aspnes, J. Vac. Sci. Technol., B: Microelectron. Nanometer Struct., 1997, 15, 12051211.

18 J. Shi, B. Hong, A. Parikh, R. Collins and D. Allara, Chem. Phys. Lett., 1995, 246, 90-94.

19 L. J. Richter, C. S.-C. Yang, P. T. Wilson, C. A. Hacker, R. D. van Zee, J. J. Stapleton, D. L. Allara, Y. Yao and J. M. Tour, J. Phys. Chem. B, 2004, 108, 12547-12559.
20 M. Prato, M. Alloisio, S. A. Jadhav, A. Chincarini, T. SvaldoLanero, F. Bisio, O. Cavalleri and M. Canepa, J. Phys. Chem. C, 2009, 113, 20683-20688.

21 E. Bittrich, M. Kuntzsch, K.-J. Eichhorn and P. Uhlmann, J. Polym. Sci., Part B: Polym. Phys., 2010, 48, 1606-1615.

22 Y. Kim, R. Collins, K. Vedam and D. Allara, J. Electrochem. Soc., 1991, 138, 3266-3275.

23 C. Barbero and R. Kotz, J. Electrochem. Soc., 1994, 141, 859865.

24 Y.-G. Mo, R. O. Dillon and P. G. Snyder, J. Vac. Sci. Technol., A, 1999, 17, 170-175.

25 S. Logothetidis, Mater. Sci. Eng., B, 2008, 152, 96-104.

26 L. Ionov, A. Sidorenko, K. Eichhorn, M. Stamm, S. Minko and K. Hinrichs, Langmuir, 2005, 21, 8711-8716.

27 R. Carpick, T. Mayer, D. Sasaki and A. Burns, Langmuir, 2000, 16, 4639-4647.

28 R. W. Carpick, D. Y. Sasaki, M. S. Marcus, M. A. Eriksson and A. R. Burns, J. Phys.: Condens. Matter, 2004, 16, R679.

29 T. Wang, A. D. F. Dunbar, P. A. Staniec, A. J. Pearson, P. E. Hopkinson, J. E. MacDonald, S. Lilliu, C. Pizzey, N. J. Terrill, A. M. Donald, A. J. Ryan, R. A. L. Jones and D. G. Lidzey, Soft Matter, 2010, 6, 4128-4134.

30 A. J. Pearson, T. Wang, R. A. L. Jones, D. G. Lidzey, P. A. Staniec, P. E. Hopkinson and A. M. Donald, Macromolecules, 2012, 45, 1499-1508.

31 T. Wang, A. J. Pearson, D. G. Lidzey and R. A. L. Jones, Adv. Funct. Mater., 2011, 21, 1383-1390.

32 I. Zudans, W. Heineman and C. Seliskar, J. Phys. Chem. B, 2004, 108, 11521-11528.

33 C. Akerlind, H. Arwin, F. L. E. Jakobsson, H. Kariis and K. Jarrendahl, Thin Solid Films, 2011, 519, 3582-3586.

34 G. Callierotti, A. Bianco, C. Castiglioni, C. Bertarelli and G. Zerbi, J. Phys. Chem. A, 2008, 112, 7473-7480.

35 F. Stellacci, C. Bertarelli, F. Toscano, M. C. Gallazzi, G. Zotti and G. Zerbi, Adv. Mater., 1999, 11, 292-295.

36 G. Pariani, R. Castagna, G. Dassa, S. Hermes, C. Vailati, A. Bianco and C. Bertarelli, J. Mater. Chem., 2011, 21, 13223-13231.

37 H. Nishi, T. Namari and S. Kobatake, J. Mater. Chem., 2011, 21, 17249-17258.

38 T. Wigglesworth, A. Myles and N. Branda, Eur. J. Org. Chem., 2005, 1233-1238.

39 J. Biteau, F. Chaput, K. Lahlil, J.-P. Boilot, G. M. Tsivgoulis, J.-M. Lehn, B. Darracq, C. Marois and Y. Lvy, Chem. Mater., 1998, 10, 1945-1950.

40 T. Kawai, N. Fukuda, D. Gröschl, S. Kobatake and M. Irie, Jpn. J. Appl. Phys., 1999, 38, L1194-L1196.

41 M.-S. Kim, H. Maruyama, T. Kawai and M. Irie, Chem. Mater., 2003, 15, 4539-4543.

42 S. Kobatake, S. Takami, H. Muto, T. Ishikawa and M. Irie, Nature, 2007, 446, 778-781.

43 M. Morimoto and M. Irie, J. Am. Chem. Soc., 2010, 132, 14172-14178.

44 S. Hermes, G. Dassa, G. Toso, A. Bianco, C. Bertarelli and G. Zerbi, Tetrahedron Lett., 2009, 50, 1614-1617.

45 G. Gonella, O. Cavalleri, I. Emilianov, L. Mattera, M. Canepa and R. Rolandi, Mater. Sci. Eng., C, 2002, 22, 359-366. 
46 R. M. A. Azzam and N. M. Bashara, Ellipsometry and Polarized Light, North-Holland, New York, 3rd edn, 1977.

47 Handbook of ellipsometry, ed. H. Tompkins and E. Irene, Andrew, Norwich, 1st edn, 2005.

48 H. Fujiwara, Spectroscopic Ellipsometry: Principles and Applications, Wiley, Chichester, United Kingdom, 1st edn, 2007.

49 M. Losurdo, M. Bergmair, G. Bruno, D. Cattelan, C. Cobet, A. de Martino, K. Fleischer, Z. Dohcevic-Mitrovic, N. Esser, M. Galliet, R. Gajic, D. Hemzal, K. Hingerl, J. Humlicek, R. Ossikovski, Z. V. Popovic and O. Saxl, J. Nanopart. Res., 2009, 11, 1521-1554.

50 T. W. H. Oates, H. Wormeester and H. Arwin, Prog. Surf. Sci., 2011, 86, 328-376.

51 D. E. Aspnes, J. Vac. Sci. Technol., A, 2013, 31, 058502.

52 M. Canepa, A Surface Scientist's View of Spectroscopic Ellipsometry, in Surface Science Techniques, ed. G. Bracco and B. Holst, Springer Series in Surface Sciences, Berlin, Germany, 1st edn, 2013, vol. 51, pp. 99-135.

53 G. E. Jellison, Jr, Appl. Opt., 1991, 30, 3354-3360.

54 J. N. Hilfiker, N. Singh, T. Tiwald, D. Convey, S. M. Smith, J. H. Baker and H. G. Tompkins, Thin Solid Films, 2008, 516, 7979-7989.

55 F. Bordi, M. Prato, O. Cavalleri, C. Cametti, M. Canepa and A. Gliozzi, J. Phys. Chem. B, 2004, 108, 20263-20272.

56 M. Prato, R. Moroni, F. Bisio, R. Rolandi, L. Mattera, O. Cavalleri and M. Canepa, J. Phys. Chem. C, 2008, 112, 3899-3906.

57 H. Hamoudi, M. Prato, C. Dablemont, O. Cavalleri, M. Canepa and V. A. Esaulov, Langmuir, 2010, 26, 7242-7247.

58 C. Toccafondi, M. Prato, G. Maidecchi, A. Penco, F. Bisio, O. Cavalleri and M. Canepa, J. Colloid Interface Sci., 2011, 364, 125-132.

59 M. Canepa, G. Maidecchi, C. Toccafondi, O. Cavalleri, M. Prato, V. Chaudhari and V. A. Esaulov, Phys. Chem. Chem. Phys., 2013, 15, 11559-11565.

60 C. Toccafondi, O. Cavalleri, F. Bisio and M. Canepa, Thin Solid Films, 2013, 543, 78-82.
61 H. Knobloch, S. Katholy, J. Hesse, H. Orendi, D. Prescher, R. Ruhmann and L. Brehmer, Mater. Sci. Eng., C, 1998, 5, 307-310.

62 J. Sworakowski, K. Janus and S. Nepurek, Adv. Colloid Interface Sci., 2005, 116, 97-110.

63 G. Pariani, A. Bianco, R. Castagna and C. Bertarelli, J. Phys. Chem. A, 2011, 115, 12184-12193.

64 T. Sosnowski and H. Weber, Appl. Phys. Lett., 1972, 21, 310-311.

65 W. M. Prest and D. J. Luca, J. Appl. Phys., 1979, 50, 60676071.

66 M. J. Dignam, M. Moskovits and R. W. Stobie, Trans. Faraday Soc., 1971, 67, 3306-3317.

67 C. Ramsdale and N. Greenham, Adv. Mater., 2002, 14, 212-215.

68 M. Campoy-Quiles, G. Heliotis, R. Xia, M. Ariu, M. Pintani, P. Etchegoin and D. Bradley, Adv. Funct. Mater., 2005, 15, 925-933.

69 M. Campoy-Quiles, P. G. Etchegoin and D. D. C. Bradley, Phys. Rev. B: Condens. Matter Mater. Phys., 2005, 72, 045209.

70 E. Kim, Y.-K. Choi and M.-H. Lee, Macromolecules, 1999, 32, 4855-4860.

71 S. Cho, M. Yoo, H.-W. Shin, K.-H. Ahn, Y.-R. Kim and E. Kim, Opt. Mater., 2003, 21, 279-284.

72 M. Irie, T. Lifka, S. Kobatake and N. Kato, J. Am. Chem. Soc., 2000, 122, 4871-4876.

73 M. Irie, S. Kobatake and M. Horichi, Science, 2001, 291, 1769-1772.

74 S. Kobatake, H. Hasegawa and K. Miyamura, Cryst. Growth Des., 2011, 11, 1223-1229.

75 S. Kobatake, K. Shibata, K. Uchida and M. Irie, J. Am. Chem. Soc., 2000, 122, 12135-12141.

76 K. Uchida, N. Izumi, S. Sukata, Y. Kojima, S. Nakamura and M. Irie, Angew. Chem., Int. Ed., 2006, 45, 6470-6473.

77 M. Morimoto, S. Kobatake and M. Irie, Chem. - Eur. J., 2003, 9, 621-627.

78 S. Yamamoto, K. Matsuda and M. Irie, Org. Lett., 2003, 5, 1769-1772.

79 T. Kodani, K. Matsuda, T. Yamada, S. Kobatake and M. Irie, J. Am. Chem. Soc., 2000, 122, 9631-9637. 